\title{
Pharmacological Treatments for GH-Induced Insulin Resistance
}

\author{
MiYuKI SUGIMOTO, NORIYUKI TAKEDA, JUNKO HATTORI, KOUJI YOSHINO, \\ KAZUYA NAKASHIMA, SHOJI OKUMURA, MASATOSHI ISHIMORI AND KEIGO YASUDA
}

3rd Department of Internal Medicine, Gifu University, Gifu 500, Japan

\begin{abstract}
Troglitazone (T) and d-chiroinositol (DCI) have been reported to improve insulin resistance associated with obesity and NIDDM. We tested whether these compounds counteract the insulin antagonistic effects of recombinant human GH. Male Wistar rats were allocated to 4 different treatment groups, rhGH $(n=8), \operatorname{rhGH}+\mathrm{T}(\mathrm{n}=7), \mathrm{rhGH}+\mathrm{DCI}(\mathrm{n}=8)$ and control (saline, $\mathrm{n}=8)$. rhGH $(2 \mathrm{IU} / 100 \mathrm{~g} / \mathrm{day})$ was injected sc twice daily for 2 days. T and DCI were given $(20 \mathrm{mg} /$ day) po for 5 days preceding and 2 days along with rhGH. Euglycemic hyperinsulinemic clamp studies were done to assess the hepatic glucose output (HGO) and glucose disappearance rate (GDR). Fasting plasma glucose, insulin, serum FFA and basal HGO were similar in all 4 treatment groups. During the hyperinsulinemic clamp which raised plasma insulin levels to $7.2 \pm 0.4 \mathrm{ng} / \mathrm{ml}$, HGO was suppressed in the control and $\mathrm{rhGH}+\mathrm{T}$ treated rats but not in the rats treated with rhGH and rhGH+DCI. GDR decreased in the rats which received $\mathrm{rhGH}(18.1 \pm 5.8 \mathrm{vs} 30.3 \pm 5.2 \mathrm{mg} / \mathrm{kg} / \mathrm{min})$ compared to the control rats. The rats given either $\mathrm{T}(24.7 \pm$ $2.7)$ or DCI $(31.4 \pm 2.7)$ along with rhGH showed comparable GDR to the control rats. These results indicated that rhGH induced hepatic and peripheral insulin resistance. Troglitazone counteracted the insulin-antagonistic action of rhGH both in the liver and the peripheral tissues. DCI was effective in offsetting peripheral insulin resistance but without any effect on hepatic insulin resistance associated with rhGH treatment.
\end{abstract}

Key words: Insulin resistance, Troglitazone, D-chiroinositol, Recombinant human GH, Hyperinsulinemic clamp

(Endocrine Journal 46: S51-S53, 1999)

RECOMBINANT gene technology has overcome the limitation of GH supply and opened the door to new therapeutic uses for GH. Adverse effects of $\mathrm{GH}$ on glucose metabolism may be a major problem in such situations. Short-term administration of $\mathrm{GH}$ to normal subjects has been reported to induce insulin resistance [1]. There are several classes of compounds with proven or proposed potency to ameliorate insulin resistance in obesity and type 2 diabetes. Among them, troglitazone, a thiazolidinedione derivative, is now clinically available for the treatment of type 2

Correspondence to: Dr. Noriyuki TAKEDA, The 3rd Department of Internal Medicine Gifu University School of Medicine 40 Tsukasamachi, Gifu 500, Japan diabetes [2], and d-chiroinositol (DCI) is under investigation [3]. The present study was designed to clarify whether troglitazone and DCI can block the insulin antagonistic effects of recombinant human $\mathrm{GH}$ in rats.

\section{Materials and Methods}

Male Wistar rats were allocated to the following four treatment groups: 1$)$ rhGH treatment $(n=8), 2)$ rhGH and $\mathrm{T}$ treatment $(\mathrm{n}=7), 3) \mathrm{rhGH}$ and DCI treatment $(n=8)$, and 4) controls $(n=8) . \quad r h G$ at a dose of $1 \mathrm{IU} / 100 \mathrm{~g}$ was administered subcutaneously in the morning and evening for 2 days. Saline instead of rhGH was injected to the control rats. 
Table 1. Metabolic characteristics of the rats

\begin{tabular}{lcccrrr}
\hline & $\begin{array}{c}\text { Body weight } \\
(\mathrm{g})\end{array}$ & $\begin{array}{c}\text { FPG } \\
(\mathrm{mg} / \mathrm{d} l)\end{array}$ & $\begin{array}{c}\text { FPI } \\
(\mathrm{ng} / \mathrm{ml})\end{array}$ & $\begin{array}{c}\text { FFA } \\
(\mathrm{mEq} / \mathrm{l})\end{array}$ & $\begin{array}{r}\text { HGO (Basal) } \\
(\mathrm{mg} / \mathrm{kg} / \mathrm{min})\end{array}$ & $\begin{array}{c}\text { HGO (Clamp) } \\
(\mathrm{mg} / \mathrm{kg} / \mathrm{min})\end{array}$ \\
\hline Control (n=8) & $203.0 \pm 2.3$ & $116.4 \pm 3.8$ & $1.06 \pm 0.2$ & $1.61 \pm 0.3$ & $10.42 \pm 0.6$ & $6.28 \pm 0.9$ \\
rhGH $(\mathrm{n}=8)$ & $208.5 \pm 4.0$ & $119.5 \pm 2.1$ & $1.09 \pm 0.1$ & $1.58 \pm 0.2$ & $8.82 \pm 1.0$ & $6.64 \pm 1.2$ \\
T+rhGH $(\mathrm{n}=7)$ & $205.5 \pm 4.5$ & $109.6 \pm 5.5$ & $1.20 \pm 0.1$ & $1.43 \pm 0.2$ & $8.96 \pm 1.7$ & $3.55 \pm 1.4$ \\
DCI+rhGH $(\mathrm{n}=8)$ & $203.6 \pm 5.7$ & $115.2 \pm 2.3$ & $1.24 \pm 0.2$ & $1.25 \pm 0.1$ & $12.15 \pm 1.4$ & $10.50 \pm 2.0$ \\
\hline
\end{tabular}

Data are means \pm SEM. FPG, fasting plasma glucose; FPI, fasting plasma insulin; FFA, free fatty acid; HGO, hepatic glucose output.

Saline or T or DCI was given to the rats by gastric gavage twice daily for 5 days prior to and 2 days along with the rhGH treatment. The total daily dose of T and DCI was $20 \mathrm{mg} /$ day.

Four days before the glucose clamp study, indwelling catheters were inserted into the right carotid artery and jugular vein of the rats.

The glucose clamp studies were done on overnight fasted conscious rats in the morning on completion of the growth hormone treatment. After basal blood sampling, primed $(6 \mu \mathrm{Ci})$ and continuous $(0.15 \mu \mathrm{Ci} / \mathrm{min})$ infusion of $\mathrm{D}-\left[3-{ }^{3} \mathrm{H}\right]-$ glucose, and human regular insulin $(287 \mathrm{pmol} /$ $\mathrm{kg} / \mathrm{min}$ for 30 seconds and subsequently 57.4 $\mathrm{pmol} / \mathrm{kg} / \mathrm{min}$ continuously) were done during the clamp. Plasma glucose was measured every $5 \mathrm{~min}$, so as to adjust the unlabeled glucose infusion rate to clamp plasma glucose at $110 \mathrm{mg} / \mathrm{d} l$.

\section{Analytical methods}

Plasma glucose and insulin were measured by the glucose oxidase method and double antibody radioimmunoassay, respectively. The specific activity of plasma glucose was measured according to Somogyi's procedure.

\section{Calculations}

The hepatic glucose output (HGO) and glucose disposal rate (GDR) were calculated according to Steel's equations. All data are shown as means \pm SEM and statistical analyses were done by oneway factorial ANOVA and Fisher's least significant difference.

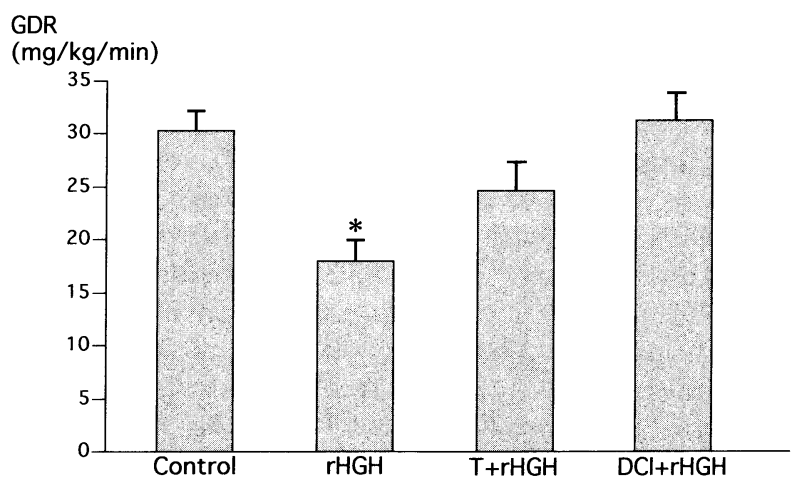

Fig. 1. Glucose disposal rate (GDR). Significant difference from the control by ANOVA $(* P<0.05)$. GDR decreased in the rHGH-treated rats but there was no difference between the $\mathrm{T}+\mathrm{rHGH}$ or $\mathrm{DCI}+\mathrm{rHGH}$ treated rats and the controls.

\section{Results}

As shown in Table 1, fasting plasma glucose, insulin, serum FFA and basal HGO were similar in all 4 groups. When plasma insulin was increased to $7.2 \pm 0.2 \mathrm{ng} / \mathrm{ml}$ during the glucose clamp, HGO was significantly suppressed below the basal value in the control rats and $\mathrm{T}+\mathrm{rhGH}$ treated rats but not suppressed in the rats treated with rhGH alone or with rhGH+DCI. The glucose infusion rate in the steady state was decreased in the rhGH group $(13.5 \pm 4.5 \mathrm{mg} / \mathrm{kg} / \mathrm{min})$ and it was comparable in $\mathrm{T}+\mathrm{rhGH}(22.4 \pm 5.9)$ and $\mathrm{DCI}+\mathrm{T}$ groups $(21.7 \pm 2.0)$ to the control level $(24.1 \pm 4.1)$. As shown in Fig. 1, the GDR decreased in the rats treated with rhGH. There was no difference in the GDR between the control rats and those treated with $\mathrm{T}+\mathrm{rhGH}$ or $\mathrm{DCI}+\mathrm{rhGH}$. Pretreatment with T or DCI prevented a decrease in GDR. 


\section{Discussion}

We demonstrated that the administration of rhGH at a dose of $2 \mathrm{IU} / 100 \mathrm{~g} /$ day for 2 days in rats decreased insulin-mediated glucose disposal during the euglycemic clamp. The effect of insulin in suppressing HGO was also impaired in these rats. These results clearly indicate the emergence of both hepatic and peripheral insulin resistance after rhGH administration in the rats. Human GH is known to bind and activate not only human but also non-primate $\mathrm{GH}$ receptors [4]. Diabetogenic actions of human GH in Wistar rat [5] and ob/ob mouse [6] have been reported. The use of rat for the study of human GH induced-insulin resistance seems to be justified. Troglitazone counteracted the insulin-antagonistic action of rhGH both in the liver and the peripheral tissues, whereas DCI was effective only in offsetting peripheral but not hepatic insulin resistance. It has been suggested that some of the insulin-antagonistic effects of GH may be induced by increased lipolysis and a subsequent increase in FFA which ultimately inhibits glucose uptake and oxidation [7]. And there is the argument that many of the effects of thiazolidinediones on glucose metabolism are secondary to reduced lipid availability [8]. These explanations, however, seem unlikely to apply in the present study. Troglitazone is thought to exert effects through binding to peroxisome proliferator activated receptor- $\gamma$ (PPAR $\gamma$ ) [2], one of the nuclear hormone receptors, and it is proposed that DCI works via incorporation into inositol glycan, a putative second messenger of insulin action [1]. Although the mechanisms of these compounds in counteracting some of the insulin-antagonistic effects of GH clearly need further investigation, these compounds may be usuful for minimizing the dibetogenic effects of $\mathrm{GH}$.

\section{References}

1. Ganda OP, Simonson DC (1993) Growth hormone, acromegaly, and diabetes. Diab Rev 1: 286-300.

2. Saltiel AR, Olefsky JM (1996) Thiazolidinediones in the treatment of insulin resistance and type II diabetes. Diabetes 45: 1661-1669.

3. Ortmeyer HK, Huang LC, Zhang LU, Hansen BC, Larner J (1993) Chiroinositol deficiency and insulin resistance. II. Acute effects of D-chiroinositol administration in streptozotocin-diabetic rats, nomal rats given a glucose load, and spontaneously insulin-resistant Rhesus monkeys. Endocrinology 132: 646-651.

4. Souza SC, Frick GP, Wang XZ, Kopchick JJ, Lobo RB, Goodman M (1995) A single arginine residue determines species specificity of the human growth hormone receptor. Proc Natl Acad Sci 92: 959-963.

5. Ng SF, Storlien LH, Kraegen EW, Stuart MC,
Chapman GE, Lazarus L (1990) Effect of biosynthetic human growth hormone on insulin action in indivisual tissue of the rat in vivo. Metabolism 39: 264-268.

6. Towns R, Kostyo JL, Colca JR (1994) Pioglitazone inhibits the diabetogenic action of growth hormone, but not its ability to promote growth. Endocrinology 134: 608-613.

7. Møller N, Jørgensen JOL, Abildgard L, Schmitz O (1991) Effects of growth hormone on glucose metabolism. Horm Res 36 (suppl 1): 32-35.

8. Oakes ND, Kennedy CJ, Jenkins AB, Laybutt DR, Chrisholm DJ, Kraegen EW (1994) A new antidiabetic agent, BRL 49653, reduces lipid availability and improves insulin action and glucoregulation in the rat. Diabetes 43: 1203-1210. 